\title{
Oligarquia, democracia e representação no pensamento de Michels
}

\author{
Oligarchy, democracy and representation \\ in Michels's thought
}

A obra de Robert Michels, em particular sua Sociologia dos partidos políticos, de 1911, representa uma contribuição que permanece importante para os estudos sobre representação política ${ }^{1}$. Sua famosa reflexão sobre a tendência à "oligarquização" dos partidos políticos entrou para o senso comum cultivado. Em geral, Michels é evocado para indicar os limites que uma certa natureza humana impõe às tentativas de organização democrática. Aqueles que detêm poder vão usá-lo, em primeiro lugar, para seu próprio benefício. A divisão funcional entre governantes e governados, entre líderes e liderados, sempre se torna mais do que uma mera divisão funcional. Torna-se uma diferenciação de interesses e - embora Michels não dê ênfase à palavra ou ao conceito - uma forma de dominação.

Essa conclusão é congruente com a reflexão e o espírito de Michels. A Sociologia dos partidos políticos é a obra que conclui o trabalho de luto das suas ilusões em relação à social-democracia alemã. A partir daí, ele caminha para o fascismo. O desencantamento com as formas de mediação política -

\footnotetext{
É professor do Instituto de Ciência Política da Universidade de Brasília (Brasília, DF). E-mail: luisfelipemiguel@gmail.com.

Este texto é fruto de minha apresentação na mesa-redonda "Robert Michels: 100 anos da lei de ferro da oligarquia", realizada no $8^{\circ}$ Encontro da Associação Brasileira de Ciência Política, em Gramado (RS), de $1^{\circ}$ a 4 de agosto de 2012. A mesa foi coordenada por Paulo Peres e contou com a participação também de André Marenco dos Santos. A versão aqui apresentada beneficiou-se dos comentários (e também das exposições) dos outros participantes da mesa e da plateia, bem como da leitura prévia e sugestões de Flávia Biroli e de Regina Dalcastagnè. Continuo, é claro, como único responsável pelos erros e omissões.
} 
começando pelo próprio partido - levou-o a encarar positivamente a pretensa relação direta entre o Duce e as massas italianas. No entanto, acredito que é possível propor uma apropriação diferente do pensamento de Michels. Em vez de nos levar ao abandono do ideal democrático, ele pode servir de alerta contra o abastardamento desse ideal pelas próprias instituições que dizem implementá-lo.

Vejo Michels como integrante da galeria de teóricos conservadores ou mesmo reacionários que têm o mérito de iluminar deficiências e questionar aspectos não problematizados do pensamento liberal. Meu esforço, neste artigo, é estabelecer uma posição aparentemente paradoxal. Por um lado, argumento que a chamada "teoria clássica das elites", que tem Michels como integrante de sua trindade de autores canônicos, é um discurso ideológico, sem maior sofisticação teórica, que hoje mantém seu interesse apenas como um capítulo da história das ideias da reação. Por outro lado, quero destacar que, em seu estudo sobre a social-democracia alemã, Michels indicou, de forma lúcida, provocativa e com algum exagero retórico, questões relativas à representação política que continuam merecendo reflexão um século depois. Juntando as duas pontas, advogo aqui por uma leitura antielitista do pensamento de Robert Michels como o melhor caminho para aproveitar aquilo que sua obra pode nos fornecer.

Na primeira seção do artigo, analiso as contribuições dos elitistas clássicos sob a chave do que Hirschman chamou de "tese da futilidade", uma das formas básicas de expressão do pensamento reacionário, buscando destacar a obra de Michels em relação a Pareto e Mosca. Na segunda seção, indico algumas das potencialidades - e também dos limites - do uso da teoria de Michels como ferramenta para pensar a representação política. Na breve conclusão, esboço o programa da leitura antielitista de Robert Michels e de sua "lei de ferro" das oligarquias.

\section{Elitismo como retórica da futilidade}

Resumido a seu conteúdo mais simples, o elitismo pode ser definido como a afirmação da impossibilidade de uma ordem social mais igualitária. A distinção entre uma minoria que exerce o poder e uma maioria que está submetida às ordens emanadas de outros seria uma constante universal, presente em qualquer sociedade humana do passado, do presente e, sem dúvida, do futuro. Qualquer tentativa de mudar essa situação está fadada 
ao fracasso. Por trás das aparências e do discurso oficial de seus líderes, todos os movimentos políticos pretensamente igualitários apenas renovam as formas de dominação das maiorias pelas minorias. A queda da Bastilha leva ao Terror, a tomada do Palácio de Inverno leva ao gulag, o assalto ao quartel de Moncada leva ao castrismo: movimentos que afirmavam estar liquidando a dominação e inaugurando uma era de igualdade derrubam minorias no poder apenas para colocar no lugar seus líderes, que se tornam minorias tão discricionárias quanto as anteriores.

Entendido dessa forma, o elitismo certamente é um modo do pensamento político muito anterior à produção do cânone hoje chamado de "clássico", na virada do século XIX para o século XX, pelas mãos de Vilfredo Pareto, Gaetano Mosca e, um pouco depois, Robert Michels. Mas é necessário não confundi-lo com a mera afirmação da desigualdade natural entre as pessoas ou mesmo da necessidade de que os melhores ou mais aptos exerçam o governo. Em grande parte do pensamento conservador, o entendimento de que as desigualdades têm base natural - e de que o governo é uma atividade que deve ser reservada a uma minoria capaz - está combinado a um alerta quanto aos riscos da anarquia, caso esses imperativos sejam desrespeitados. É possível pensar, por exemplo, na obra fundadora do conservadorismo moderno, o livro sobre a Revolução Francesa escrito por Edmund Burke (1982 [1790]). Ele não fala sobre a imutabilidade de uma ordem; adverte sobre o perigo de subvertê-la.

Tal como o apresento aqui, o elitismo tem como característica distintiva a afirmação de que uma sociedade igualitária não tem como se efetivar. Ele aponta não para a ameaça da anarquia, já que ela é, em seus próprios termos, uma impossibilidade. Aponta, isso sim, para a vacuidade dos esforços de quem planeja uma reforma da sociedade nessa direção, ao mesmo tempo em que denuncia seu discurso como ilusório e enganoso. Trata-se, portanto, de uma corrente de pensamento que ilustra com perfeição aquilo que Albert Hirschman (1992 [1991]) chama de "tese da futilidade", um dos modos fundamentais do discurso reacionário: qualquer tentativa de mudar o mundo é fútil, pois o mundo sempre volta a ser aquilo que, em essência, ele é. E, nesse caso, em essência o mundo social é a dominação da massa pela elite.

Em seu ensaio, com a erudição e a vivacidade que marcam suas melhores obras, Hirschman identifica a futilidade como uma das três teses invocadas pela retórica reacionária, ao lado da perversidade (qualquer tentativa de 
transformação do mundo provoca o seu oposto) e da ameaça (as tentativas de mudanças comprometem a realização de valores tão ou mais importantes quanto aqueles que são buscados por elas). Evidentemente, as teses devem ser entendidas como tipos ideais; os discursos reacionários reais mesclam-nas em diferentes proporções. Os teóricos das elites aparecem como representantes importantes da tese da futilidade, que Mosca, Pareto e Michels desenvolveram "sistematicamente em muitas direções" (Hirschman, 1992 [1991], p. 55). Mas também são citados, com destaque, Tocqueville, por sua conhecida interpretação da Revolução Francesa como mero prosseguimento de tendências em curso no Ancien Régime (Hirschman, 1992 [1991], p. 45-48), e, na literatura mais recente, os autores que buscam provar que o Welfare State foi incapaz de promover melhorias na situação relativa dos mais pobres (Hirschman, 1992 [1991], p. 56-63) ${ }^{2}$.

Não me interessa, aqui, entrar em detalhes do pensamento de Pareto, de Mosca ou mesmo do próprio Michels, para mostrar como cada um deles constrói, à sua própria maneira, esse argumento da futilidade (cf. Miguel, 2002). O que é significativo é que a teoria surge no momento em que a aparente indiscutibilidade de sua tese central estava sob ameaça. É quando o movimento democrático e o movimento socialista ganham força na Europa, com suas promessas de superação da desigualdade, que parece necessário afirmar que ela nunca desaparecerá.

Em outro livro, o mesmo Hirschman comenta o sucesso da obra de Mancur Olson - que é, à sua maneira, um atualizador do pensamento elitista. Quando foi publicado em 1965, As duas lógicas da ação coletiva passou quase despercebido. O livro só vai ganhar importância após os eventos de maio de 1968. Segundo Hirschman, a teoria de Olson deve sua popularidade ao fato de que servia para acalmar o establishment, pois demonstrava que a rebelião operária e juvenil não podia ter acontecido (Hirchman, 1983 [1982], p. 86). Pode-se dizer que, na virada do século XIX para o XX, a teoria clássica das elites cumpria um papel tranquilizador similar.

É possível fazer um paralelo com a filosofia de Nietzsche, em grande medida contemporânea de Pareto e Mosca, e que representa, em muitos

Na mesa "Robert Michels: 100 anos da lei de ferro da oligarquia", já mencionada, André Marenco dos Santos observou que Michels incorporaria a tese da perversidade: a organização destinada a promover a emancipação da classe operária passaria a dominá-la. De fato, é um elemento digno de atenção. Mas creio que, como narrativa geral, a obra de Michels continua mais identificada com a tese da futilidade: a busca de uma sociedade igualitária culmina em uma nova sociedade desigual. 
sentidos, uma radicalização do pensamento elitista ${ }^{3}$. O esforço de Nietzsche é demonstrar que somos, por natureza, divididos entre aqueles dotados de vontade de poder, portanto votados ao mando, e o rebanho dos homens fracos, carentes de vontade de poder, destinados a serem comandados. $\mathrm{O}$ drama da sua época, porém, era a "revolta dos escravos" - aqueles destinados a serem dominados estavam se revoltando contra seu destino. Nos termos da própria filosofia de Nietzsche, trata-se de uma contradição em termos, de uma impossibilidade lógica. O rebanho permanece nessa condição porque percebe nela algo adequado à sua própria natureza e o fato de assim perceber é a marca mesma do pertencimento de cada um ao rebanho.

Mas é essa impossibilidade que apavora o filósofo. Tal como o de Nietzsche, o pensamento dos elitistas clássicos é também perpassado por essa contradição entre um artigo de fé teórico (a impossibilidade da igualdade) e uma tomada de posição política (a necessidade de trabalhar ativamente para evitar a igualdade). A ação política do rebanho é considerada, a um só tempo, como uma impossibilidade, um risco e uma degeneração, estando marcada pelo "ressentimento" - um tema caro a Nietzsche, que dessa forma estigmatiza as demandas por igualdade como sendo a expressão de uma emoção menor e negativa.

Hoje, uma sociedade plenamente igualitária parece um sonho improvável. O próprio sentido de "igualdade" é tema para uma polêmica sem fim, muito longe do sentido quase autoevidente que tinha para os teóricos das elites e para seus adversários. Discutimos qual é a relação entre igualdade e diferença ou se nosso ideal deve ser uma igualdade de recursos, de bem-estar ou mesmo de oportunidades (cf., entre muitos outros, Phillips, 1999; Dworkin, 2000).

As disputas teóricas e políticas em torno do conceito de igualdade expõem, ainda mais, as simplificações que estão na base do pensamento de Pareto, de Mosca ou de Michels. Seria possível apontar formas de organização social em que o domínio da minoria, indicado pelos elitistas, simplesmente não existe, como as sociedades "contra o Estado", para lembrar o título da famosa obra do antropólogo francês Pierre Clastres (1988 [1974]). Em livro recente, o cientista político James Scott analisa as estratégias de povos que viviam na periferia dos Estados e se esforçavam por garantir o mínimo de autoridade governamental. Enquanto o avanço tecnológico não tornou irrelevantes as barreiras físicas, os "povos das montanhas" constituíam comunidades vir- 
tualmente autônomas e, em muitos casos, internamente igualitárias (Scott, 2009). Enfim, quando analisada com um pouco mais de cuidado, a constante universal e imutável dos elitistas se mostra circunscrita historicamente.

Mas não é preciso ir tão longe. A expressão "minoria governante" pode significar muitas coisas diferentes. É possível identificar a presença de uma minoria governante na democracia ateniense do século IV a.C., bem como no Império Otomano, em alguma monarquia absoluta europeia do século XVII, na Alemanha hitlerista, na Síria da família Assad ou no Brasil do início do século XXI. São todos governos de minoria. No entanto, pouco há em comum entre eles e nada justifica vê-los como meras manifestações de uma característica trans-histórica, como justificações da regra de que o governo é uma tarefa de elite ou como demonstrações do postulado de que a oligarquia é "a forma prestabelecida da vida em comum dos grandes agregados sociais" (Michels, 1982 [1911], p. 235).

Nos variados exemplos que citei, podemos observar diferenças profundas no que se refere às origens dos governantes e à forma pela qual são recrutados; à densidade e à natureza das trocas entre governantes e governados; ao elenco de interesses que precisam ser levados em conta (e em que medida) no processo decisório; à capacidade de pressão e aos mecanismos de controle e supervisão dos governados sobre os governantes; aos limites em que o uso da força é aceito como instrumento legítimo de governo. Nada disso, porém, entra na conta da teoria das elites.

Em uma observação lateral, Michels admite que, dentro de "certos limites, muito estreitos", há um efeito igualitário advindo da existência de um partido democrático: "a importância que é atribuída às massas aumenta, mesmo que elas sejam guiadas por demagogos; os órgãos da legislação e da administração se habituam a ceder, não mais apenas às pretensões vindas de cima, mas também às exigências vindas de baixo" (Michels, 1982 [1911], p. 219). Mas não alcança a conclusão que se imporia a partir daí, isto é, que a divisão entre quem governa e quem é governado assume diferentes feições, de acordo com a correlação de forças na sociedade, e que essas diferenças importam mais do que o postulado banal de que alguns exercem funções de governo e outros, não.

Em suma, a doutrina elitista é apenas uma justificação ideológica da desigualdade política, baseada numa filosofia da história que é simplista teoricamente e equivocada empiricamente. 
Dentro desse quadro, qual a especificidade da contribuição de Robert Michels? Em primeiro lugar, o método de trabalho. Enquanto Pareto e Mosca partiam de uma teorização geral e daí fisgavam na história da humanidade os exemplos que melhor se adequavam ao que queriam dizer, Michels buscava um caminho inverso. Sua "lei de ferro das oligarquias" é uma generalização a partir de um estudo parcial, mas minucioso, sobre a social-democracia alemã. Isso confere a ele uma sensibilidade muito maior à dinâmica concreta das interações políticas.

Talvez como decorrência disso, Michels, ao contrário de Pareto e de forma mais profunda que Mosca, dá importância à relação entre a elite e a base. Ele introduz, então, a dimensão da discussão sobre a representação política. Suas oligarquias não são minorias autoinstituídas que exercem o poder político por conta de características distintivas que as colocam em posição superior de forma quase automática. É o que ocorre com os "resíduos" de Pareto, por exemplo, qualidades inatas que garantiriam, a quem as possuísse, uma posição na elite (cf. Pareto, 1935 [1916]). As oligarquias de Michels têm sua força ligada à importância de uma base social, que lhes dá ou em algum momento lhes deu sustentação e que é a razão original para que ocupem posições de poder.

Assim, a questão que Michels coloca - e que está ausente por completo das preocupações dos dois outros teóricos clássicos da elite - é o dilema próprio de qualquer movimento de massas: a busca de ampliação da eficácia de sua ação exige uma profissionalização que leva, por sua vez, à independentização da direção em relação à base. Michels explica o processo da seguinte maneira:

À medida que o trabalho político se complica e que as regras da legislação social se multiplicam é preciso, para orientar-se na política, possuir uma experiência cada vez maior e conhecimentos cada vez mais amplos. Por isso o fosso que separa os chefes do grosso do partido alarga-se cada vez mais, e chega um momento em que os primeiros perdem todo o sentimento de solidariedade para com a classe de onde saíram. Produz-se, então, uma verdadeira divisão em sub-classes: a dos capitães ex-proletários, e a dos soldados proletários (Michels, 1982 [1911], p. 54).

O trecho é exemplar por incorporar, de forma sintética, alguns dos eixos principais da argumentação de Michels. A diferenciação entre direção e base se amplia como efeito da maior complexidade do jogo político, que 
passa a exigir uma expertise própria, que não é acessível a todos. Com isso, a capacidade de interlocução entre lideranças e base fica comprometida. Cabe observar que não é só que os liderados perdem a capacidade de supervisionar os líderes; estes últimos também passam a perceber como inúteis suas tentativas de justificar-se diante de uma massa que não os entende. Assim, em vez de controle, a relação do liderado com o líder torna-se de obediência. É uma relação similar à do paciente com o médico, que também é de uma obediência baseada na confiança em um conhecimento superior (Michels, 1982 [1911], p. 56) ${ }^{4}$. A menção à multiplicação da legislação social indica que, ao menos em parte, a ampliação da complexidade da luta política é efeito das conquistas obtidas pelo próprio movimento operário.

O elemento mais importante, porém, é o esgotamento da solidariedade para com a classe de origem. Na leitura de Michels, que aqui preserva algo de sua bagagem marxista prévia, trata-se de um efeito automático da mudança de posição nas relações sociais de produção. Segundo ele, "é uma lei social inelutável que qualquer órgão da coletividade, nascido da divisão do trabalho, cria para si, logo que estiver consolidado, um interesse especial" (Michels, 1982 [1911], p. 234). O burocrata partidário ou o parlamentar não encontram mais vantagem material na melhoria das condições de vida dos operários. É isso que provoca a bifurcação dos interesses.

É possível dizer que a solução encontrada por Michels peca por seu simplismo. As motivações dos agentes políticos, no seu relato, são de um materialismo bastante grosseiro e imediato. $\mathrm{O}$ fato de que a manutenção da solidariedade com a base é a razão da permanência na posição de liderança política não é levado em conta, muito menos qualquer vinculação a projetos ou valores políticos. A incapacidade de distinguir entre o político e o funcionário, como fez Weber (1993 [1917]) na mesma época, aplaina diferenças que são importantes e retira, do horizonte de Michels, motivações para a ação política que vão além da busca de benesses que, em última análise, define seu oligarca.

Além disso, Michels desenha de forma demasiado cortante a distinção entre a elite oligárquica e sua base de massa, não levando em conta, na sua

\footnotetext{
Uma tentativa de teorizar uma forma de representação política baseada na "confiabilidade" de representantes sobre os quais os representados não têm nenhuma possibilidade de controle é encontrada no modelo"giroscópico" de Mansbridge (2003). Nos limites deste artigo, não cabe discutir a qualidade democrática dessa representação.
} 
generalização final, nem a estrutura hierárquica piramidal, que é própria dos partidos políticos e de outras organizações de massa, nem o papel de outras lideranças internas, à margem da hierarquia institucional. Dirigentes e base não se limitam a duas posições polares, mas formam um continuum de posições, em que, portanto, há circulação de informações e desafios potenciais internos que tornam mais matizada e complexa a independentização da direção. Uma vez mais, Michels é sensível ao fenômeno e anota, à margem de seu raciocínio principal, que o temor da ascensão dos "novos chefes" obriga o "velho chefe" a "manter-se em contato permanente com as opiniões e os sentimentos da massa, a quem ele deve o seu cargo, confessar-se seu instrumento e submeter-se aparentemente, pelo menos, a seu bel-prazer" (Michels, 1982 [1911], p. 95).

Essa observação leva fatalmente a um entendimento mais matizado da independentização da liderança política. A massa não está à mercê dos chefes, aos quais, em sua gratidão e incompetência, ela obedece cegamente, como, em outro trecho, diz o próprio Michels (1982 [1911], p. 40). Ela é a juíza de uma disputa interna por liderança, cuja dinâmica pode impor freios à independentização dos chefes. Mas esse aspecto é descartado na enunciação da lei de ferro das oligarquias.

Por fim, para encerrar esse breve inventário das insuficiências da formulação teórica de Michels, ele não dá nenhum espaço a mecanismos horizontais de coordenação. Mesmo que aceitemos que toda organização leva à produção de uma hierarquia, o funcionamento dessa organização, dirigido e facilitado pela hierarquia, ou ainda proporcionado pela hierarquia, exige cotidianamente formas de coordenação horizontal entre seus integrantes. Até em estruturas com uma cadeia de comando altamente formalizada e vertical, como é o caso do exército, esse tipo de coordenação é imprescindível. $\mathrm{Ou}$ seja: é justo entender que a divisão entre líderes e liderados, com a especialização funcional dos primeiros, gera assimetrias que são danosas do ponto de vista dos valores democráticos. Mas o retrato de uma base atomizada, desprovida de qualquer meio de supervisão ou de ação autônoma, à mercê de uma direção que se oligarquiza, é uma enorme simplificação.

\section{A representação e seus dilemas}

É claro que o duradouro sucesso da fórmula de Michels depende dessa simplificação. Um modelo mais sofisticado não atingiria a força imagética e 
a sedução retórica que a "lei de ferro das oligarquias" possui. Então, é dessa forma, simplificada e simplificadora, mas por isso mesmo impactante, que Michels nos defronta com um problema central para a discussão da democracia, que é a tendência à autonomização dos representantes em relação a seus representados.

A promessa central da democracia representativa é que o povo exercerá o poder mesmo estando ausente dos locais de exercício do poder. Como sabemos, é uma promessa muito ambiciosa. Uma grande parte da teoria política simplesmente se desvencilhou dela, deslocando o sentido de democracia. No lugar do governo do povo, entra a competição entre as elites. Poucos autores, hoje, assumirão na plenitude a definição crua de Schumpeter (1976 [1942]), para quem o método democrático nada mais é do que o processo ritualístico de produção de um governo legítimo, nas condições da sociedade contemporânea, sem qualquer conteúdo vinculado a alguma vontade popular. Mas, sem dúvida, como observou há alguns anos Chantal Mouffe (2005 [2000], p. 3-4), para a maior parte do pensamento político atual a democracia se resume à combinação entre o Estado de Direito e o respeito aos direitos humanos. Não é possível negar que a vigência do Estado de Direito e a proteção aos direitos humanos são valiosas, mas elas estão longe de configurar o exercício da soberania popular.

Para quem ainda busca levar a sério a promessa básica da democracia, o vínculo entre representantes e representados é uma questão-chave. É possível, uma vez mais, tentar escapar da discussão, adotando modelos que simplesmente postulam que o representante está a serviço dos representados, como aqueles de agente e mandante (que uma tradução infeliz do inglês disseminou no Brasil sob o nome de "agente-principal"). Mas, para isso, ignoram-se os diferenciais de recursos materiais, informacionais, simbólicos e cognitivos que impedem que se veja o representado e o representante como dois indivíduos racionais simétricos.

São muitos os fatores que trabalham na direção da fragilização do vínculo entre o representado e seu representante. As estruturas do campo político exigem a especialização do trabalho político, gerando um hiato de informação e de competência entre representantes e representados. E, ao mesmo tempo, estimulam a acomodação com a ordem vigente, quer pela cooptação, com a concessão de privilégios e vantagens de diferentes tipos, quer pelo incentivo à barganha e à acomodação, próprias dos regimes eleitorais e parlamentares. 
Uma organização com plataforma política radical, caso se mantenha fiel a ela, está fadada a um longo período de marginalização antes da conquista, muito incerta aliás, do poder. É grande o incentivo para que ela "entre no jogo", obtendo vitórias menores em troca da moderação do programa e da legitimação do sistema como um todo.

O próprio Michels anotou que a dinâmica da disputa eleitoral conduz o partido operário a abandonar seu compromisso de classe para tornar-se o "partido do povo" (Michels, 1982 [1911], p. 155) - um insight que, muitos anos depois, seria desenvolvido com rigor por Adam Przeworski (1989 [1985]). Assim, por um lado, os líderes partidários são extraídos da condição de vida própria de sua base e aproximam-se dos setores da elite, com os quais convivem nos diferentes espaços de exercício do poder. Por outro, a moderação na atuação e a abertura do discurso para diferentes grupos sociais (que leva à necessidade de conciliação das divergências) aparecem como imperativos da efetividade da ação política ${ }^{5}$.

O drama da oligarquização da direção política, é claro, só é sentido pelos grupos dominados. Cabe lembrar que o partido que Michels estudou tinha como objetivo declarado a promoção de uma transformação completa da sociedade alemã, em nome das camadas menos privilegiadas. Na Alemanha, como no resto do mundo, a ruptura entre a ala esquerda da social-democracia, que acabaria por adotar o rótulo de "comunista", e a ala direita, que reteve o nome, só ocorreria a partir da eclosão da I Guerra Mundial, alguns anos depois da publicação de Sociologia dos partidos políticos. E apenas em seu Congresso de Bad Godesberg, em 1959, os sociais-democratas alemães abandonaram formalmente a ideia de luta de classes, a vinculação doutrinária com o marxismo e a proposta de edificação de uma sociedade socialista.

Assim, a oligarquização não se refere simplesmente ao fato de que os dirigentes passam a defender interesses próprios, diferenciados da base. É que eles se tornam conservadores, receosos de transformar uma situação que lhes dá vantagens (ainda que secundárias), traindo, com isso, os ideais que os ligavam àqueles que dizem representar. Michels aborda a questão de

Sob esse ponto de vista, Michels parece concordar com a visão de Lênin, para quem a democracia eleitoral era a forma padrão da dominação burguesa no mundo contemporâneo. Na ausência de liberdade de competição eleitoral, o partido bolchevique foi capaz de evitar a cooptação e manter a radicalidade. Ainda assim, são também perceptíveis nele muitos dos elementos indicados na oligarquização de Michels, como a assimetria entre direção e base ou a transformação da organização num fim em si mesmo. 
diferentes ângulos. Por um lado, observa que o poder é sempre conservador (Michels, 1982 [1911], p. 219), assim como todas as formas de posse (Michels, 1982 [1911], p. 223). Por outro, anota que os líderes socialistas envelhecidos deixam de acreditar nos ideais do partido, mas não podem renegá-los em público, pois com isso minariam sua própria posição de liderança. Tornam-se, então, oportunistas, "céticos [...] cujas ações não são mais guiadas senão pela frieza do seu cálculo" (Michels, 1982 [1911], p. 120). O destino do partido operário, então, é ser dirigido por uma casta de oligarcas conservadores e hipócritas. Mas convém lembrar que, como a ação política não depende da sinceridade e sim da estabilidade dos compromissos, o fato de que a identificação dos líderes com os ideais socialistas seja um imperativo pragmático (em vez de uma opção genuína) não reduz seu impacto na condução política.

Michels tocou no ponto principal quando vinculou a oligarquização à eficiência do trabalho da organização. De fato, as experiências inovadoras de organização política, voltadas a combater as tendências oligárquicas, logo se defrontam com a compreensão de que, para fazê-lo, precisam sacrificar a eficácia de sua ação. Medidas voltadas a promover a despersonalização da liderança, a transferência de autoridade para a base ou a ampliação do debate interno geram morosidade, perda de expertise e redução da unidade de ação.

Dois exemplos citados com certa frequência são os Verdes alemães e o Partido dos Trabalhadores brasileiro, ambos fundados em 1980 e com forte preocupação com a vitalidade da democracia interna. A plataforma dos Verdes anunciava a criação de "um novo tipo de organização partidária, com estruturas descentralizadas desenhadas de acordo com os princípios da democracia de base" (apud Poguntke, 1992, p. 240-241). Era proibida a acumulação de funções, a presidência do partido era um cargo coletivo, e foi obrigatória até mesmo a alternância entre mulheres e homens nos postos de direção e nas candidaturas às eleições (Padgett e Paterson, 1996 [1994], p. 152-153). A partir dos anos 1990, porém, conforme o partido ganhava peso eleitoral e a possibilidade efetiva de partilhar o exercício do poder, houve uma adaptação gradual às formas convencionais de organização, bem como a moderação programática. Sob a liderança de Joschka Fischer, não por acaso expoente da ala "realista" (em oposição à chamada "fundamentalista") do partido, os Verdes encerraram o experimentalismo democrático interno.

Também o PT brasileiro nasceu sob o signo do novo, em que avultavam o compromisso com os movimentos sociais e os trabalhadores, a intransigência 
quanto a seus princípios, que separavam com nitidez um "nós" e um "eles" dentro do campo político, e a busca por práticas de democracia interna. A partir do momento em que o partido deixou de ocupar uma posição marginal no jogo político e uma vitória eleitoral se colocou no horizonte, o que ocorreu sobretudo a partir da eleição presidencial de 1989, o PT iniciou sua guinada pragmática, que o levou à adaptação às práticas políticas correntes. As mudanças foram perceptíveis na plataforma partidária e nos programas de governo (Amaral, 2003), na prática administrativa, nos padrões de recrutamento parlamentar, na geografia do voto (Terron e Soares, 2010), no discurso de campanha (Miguel, 2006) ou nos padrões de coligação (Miguel e Machado, 2010). E também, é claro, nas formas de organização interna (Leal, 2005; Ribeiro, 2010; Hunter 2010), com a ampliação do poder das bancadas de parlamentares e dirigentes, o fim das consultas às bases e o afastamento das vozes dissidentes.

Em diferentes graus e de diferentes maneiras, as experiências dos Verdes alemães e do PT brasileiro ilustram uma mesma situação: o imperativo de maior eficiência na ação fez recuarem os mecanismos antioligárquicos internos. A "lei" de Michels, porém, não seria válida apenas para os partidos políticos. Qualquer organização coletiva estaria sujeita a ela, que assim se estenderia a sindicatos, a associações, a movimentos sociais "novos" ou "antigos".

Mas, a cada nova geração, também vemos novas tentativas de lutar contra essa tendência. Os novos ativismos atuais são exemplos disso, com suas propostas horizontais, "rizomáticas" ou mesmo abertamente individualistas, apoiando-se nas novas tecnologias da comunicação para tentar superar gargalos organizacionais anteriores. Talvez esse experimentalismo seja uma concessão à relativa desimportância desses ativismos. Talvez ele indique mais a busca de autoexpressão, por parte de indivíduos descontentes com a ordem do mundo, do que de uma ação coletiva capaz de transformar essa ordem. Talvez, mais adiante, imperativos de eficiência se façam sentir e levem à oligarquização ${ }^{6}$. Ainda assim, é difícil negar o impacto que a maior disponibilidade de informação e a maior facilidade de coordenação horizontal têm para as formas de organização.

\footnotetext{
Em entrevista a um jornal brasileiro, o ativista Kalle Lasn, um dos criadores do movimento Occupy Wall Street, indicou que um dos motivos de seu esgotamento foi a falta de líderes que impusessem um rumo à ação, sem discussões intermináveis: "Não havia um líder, ninguém tinha o direito de falar 'Calados!'" (Fernandes, 2012, p. A-14).
} 
Cabe lembrar também que o déficit de eficácia das organizações antioligárquicas não é um dado da natureza. As condições de ação eficaz são produto da organização do campo. Determinados padrões de organização da ação política se mostram mais eficazes diante de um ambiente conformado por instituições e por práticas que se estabeleceram historicamente de determinada maneira. Caso o ambiente fosse outro, as condições de eficácia também se transformariam. O nó górdio a ser cortado (e longe de mim pretender que empunho a espada em minhas mãos) é como agir eficazmente num campo político que favorece objetivamente a organização oligárquica, mas com o intuito de transformar esse viés.

\section{Conclusões}

Robert Michels é, a meu ver, um companheiro importante nessa reflexão. Ele nos ajuda, acima de tudo, a evitar soluções fáceis. É próprio da política que as boas intenções sejam atropeladas pela necessidade de que a ação surta efeitos - uma lição que, cinco séculos depois de Maquiavel, continua atual. É fácil imaginar um modelo organizacional em que não haja diferenças de poder ou de influência entre os integrantes. É menos fácil implementá-lo, uma vez que as assimetrias não se expressam apenas formalmente (para uma discussão do ponto, com base em pesquisa sobre organizações alternativas, cf. Mansbridge, 1983 [1980]). E ainda menos fácil fazer com que uma organização assim seja capaz de competir em condição de igualdade com outras, mais centralizadas, mais disciplinadas e mais ágeis.

Em especial, Michels contribui para pensar os problemas da representação política. Nos últimos anos, um crescente corpo de literatura tem exaltado as virtudes da representação, que é descrita como a efetivação mais plena do ideal democrático (por exemplo, Urbinati, 2006; Saward, 2010). Michels nos ajuda a lembrar que a representação, embora seja a única solução para buscarmos um governo popular nas condições das sociedades contemporâneas, é também sempre um problema para a democracia. E que, portanto, não podemos descuidar da tarefa de ampliar a capacidade de interlocução entre representantes e representados e de buscar mecanismos que refreiem as tendências à autonomização destes últimos.

Há autores que contribuem para vislumbrar alternativas, que ajudam a indicar as potencialidades de mudança no mundo real e, assim, a impedir a reificação daquilo que existe hoje. Mas há autores que são como âncoras, 
que nos impedem de nos perder no sonho do "outro mundo possível", alertando sobre a força dos mecanismos de reprodução das estruturas existentes e sobre a resiliência da dominação. Autores que fazem ver que mesmo os movimentos por mudanças estão, em alguma medida, tingidos por elementos de reprodução.

Muitas vezes, os autores-âncora são pensadores conservadores, como é o caso do próprio Michels, mas nem sempre ${ }^{7}$. O que eles sempre são é "estraga-prazeres", que mostram que a transformação do mundo é mais difícil, mais complexa e menos retilínea do que gostaríamos de pensar. Eles nos lembram que não é possível desprezar os mecanismos que favorecem as permanências e que a suspensão deles na crítica não corresponde a seu desaparecimento na realidade.

Justamente por isso, são imprescindíveis. A obra de Michels é útil não para assumirmos suas conclusões relativas à impossibilidade da democratização ou sua pretensa "lei" social imutável. Ela é útil para que, de uma perspectiva radicalmente democrática, nós sejamos capazes de fazer a crítica da representação política e de evitar atalhos na tarefa de democratização efetiva da política. Ela ajuda a lembrar que a relação entre representantes e representados é uma relação assimétrica e que envolve o exercício de poder dos primeiros sobre os segundos; que não podemos levantar nossa desconfiança em relação à substituição dos representados por seus representantes. Enfim, que a democracia é um projeto sempre inacabado, que exige o combate permanente contra as formas de dominação e desigualdade que se produzem no mundo social.

\section{Referências bibliográficas}

AMARAL, Oswaldo E. do (2003). A estrela não é mais vermelha: as mudanças no programa petista nos anos 90. São Paulo: Garçoni.

BURKE, Edmund (1982 [1790]). Reflexões sobre a revolução em França. Brasília: Editora UnB.

CLASTRES, Pierre (1988 [1974]). A sociedade contra o Estado: pesquisas de antropologia política. Rio de Janeiro: Francisco Alves.

DWORKIN, Ronald (2000). Sovereign virtue: the theory and practice of equality. Cambridge (MA): Harvard University Press.

Os frankfurtianos são exemplos de "âncoras"alinhados à busca da transformação social. Outro exemplo é Pierre Bourdieu. 
FERNANDES, Sofia (2012). “Modelo do 'Ocupe Wall St.' se esgotou e perdeu a magia”. Entrevista com Kalle Lasn. Folha de S. Paulo, 9 de setembro, p. A-14.

HIRSCHMAN, Albert O. (1983 [1982]). De consumidor a cidadão: atividade privada e participação na vida pública. São Paulo: Brasiliense. (1992 [1991]). A retórica da intransigência: perversidade, futilidade, ameaça. São Paulo: Companhia das Letras.

HUNTER, Wendy (2010). The transformation of Workers' Party in Brazil, 1989-2009. Cambridge: Cambridge University Press.

LEAL, Paulo Roberto Figueira (2005). O PT e o dilema da representação política: os deputados federais são representantes de quem? Rio de Janeiro: FGV Editora.

MANSBRIDGE, Jane (1983 [1980]). Beyond adversary democracy. Chicago: The University of Chicago Press.

(2003). "Rethinking representation". American Political Science Review, v. 97, n. 4, p. 515-528.

MICHELS, Robert (1982 [1911]). Sociologia dos partidos políticos. Brasília: Editora UnB.

MIGUEL, Luis Felipe (2002). "A democracia domesticada: bases antidemocráticas do pensamento democrático contemporâneo". Dados, v. 45, n. 3 , p. $483-511$.

(2006). "From equality to opportunity: transformations in the discourse of Workers' Party in the 2002 elections”. Latin American Perspectives, v. 33, n. 4, p. 122-143.

MIGUEL, Luis Felipe \& MACHADO, Carlos (2010). "De partido de esquerda a partido de governo: o PT e suas coligações para prefeito (2000 a 2008)”, em KRAUSE, Silvana; DANTAS, Humberto \& MIGUEL, Luis Felipe (orgs.). Coligações partidárias na nova democracia brasileira: perfis e tendências. São Paulo: Editora Unesp; Rio de Janeiro: Fundação Konrad Adenauer. MOUFFE, Chantal (2005 [2000]). The democratic paradox. London: Verso.

PADGETT, Stephen \& PATERSON, Willian (1996 [1994]). "Alemanha: estagnação da esquerda”, em ANDERSON, Perry \& CAMILLER, Patrick (orgs.). Um mapa da esquerda ocidental. Rio de Janeiro: Contraponto. PARETO, Vilfredo (1935 [1916]). The mind and society: a treatise on general sociology. 4 vols. New York: Harcourt, Brace. 
PHILLIPS, Anne (1999). Which equalities matter? London: Polity.

POGUNTKE, Thomas (1992). "Unconventional participation in party politics: the experience of the German Greens”. Political Studies, v. XL, n. 2, p. 239-254.

PRZEWORSKI, Adam (1989 [1985]). Capitalismo e social-democracia. São Paulo: Companhia das Letras.

RIBEIRO, Pedro Floriano (2010). Dos sindicatos ao governo: a organização nacional do PT de 1980 a 2005. São Carlos: Editora UFScar.

SAWARD, Michael (2010). The representative claim. Oxford: Oxford University Press.

SCHUMPETER, Joseph A. (1976 [1942]). Capitalism, socialism and democracy. New York: Harper Perennial.

SCOTT, James C. (2009). The art of not being governed: an anarchist history of upland Southeast Asia. New Have: Yale University Press.

TERRON, Sonia Luiza \& SOARES, Gláucio Ary Dillon (2010). “As bases eleitorais do PT: do distanciamento ao divórcio”. Opinião Pública, v. 16, n. 2, p. 310-337.

URBINATI, Nadia (2006). Representative democracy: principles \& genealogy. Chicago: The University of Chicago Press.

WEBER, Marx (1993 [1917]). Parlamento e governo na Alemanha reordenada: crítica política do funcionalismo e da natureza dos partidos. Petrópolis: Vozes.

\section{Resumo}

A chamada "teoria das elites", que tem em Robert Michels um de seus autores canônicos, é um corpo doutrinário que visa demonstrar a impossibilidade de um ordenamento social mais democrático e igualitário. É, assim, um exemplo da "tese da futilidade", discutida por Albert Hischman, que afirma que qualquer tentativa de mudar o mundo é inútil. $O$ artigo argumenta que, apesar disso, a "lei de ferro das oligarquias", apresentada por Michels em 1911, pode ser apropriada por uma reflexão comprometida com o avanço da democracia. Em vez de levar ao abandono do ideal democrático, serve de alerta contra o abastardamento desse ideal pelas próprias instituições que dizem implementá-lo, proporcionando instrumentos para uma análise crítica da representação política.

Palavras-chave: teoria das elites; representação política; oligarquia; democracia; Robert Michels. 


\section{Abstract}

The so-called "elite theory", of which Robert Michels was one of the canonical authors, is a body of doctrine which aims to demonstrate the impossibility of a more democratic and egalitarian social order. It is thus an example of the "futility thesis" discussed by Albert Hirschman, which states that any attempt to change the world is useless. The article argues that, despite this, the "iron law of oligarchy" presented by Michels in 1911 may be appropriate for a reflection committed to the advancement of democracy. Instead of leading to the abandonment of the democratic ideal, it serves as a warning against bastardization of that ideal by the very institutions who claim to implement it, providing tools for a critical analysis of political representation.

Keywords: elite theory; political representation; oligarchy; democracy; Robert Michels.

Recebido em 30 de setembro de 2013.

Aprovado em 14 de novembro de 2013. 